\title{
Hypervolemia induces and potentiates lung damage after recruitment maneuver in a model of sepsis-induced acute lung injury
}

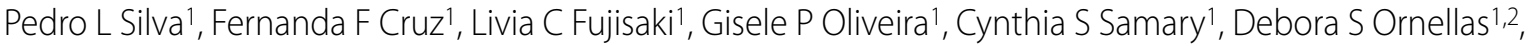 \\ Tatiana Maron-Gutierrez'1,2, Nazareth N Rocha3,4, Regina Goldenberg33, Cristiane SNB Garcia'1, Marcelo M Morales², \\ Vera L Capelozzi5, Marcelo Gama de Abreu6, Paolo Pelosi7 and Patricia RM Rocco*1
}

\begin{abstract}
Introduction: Recruitment maneuvers (RMs) seem to be more effective in extrapulmonary acute lung injury (ALI), caused mainly by sepsis, than in pulmonary ALI. Nevertheless, the maintenance of adequate volemic status is particularly challenging in sepsis. Since the interaction between volemic status and RMs is not well established, we investigated the effects of RMs on lung and distal organs in the presence of hypovolemia, normovolemia, and hypervolemia in a model of extrapulmonary lung injury induced by sepsis.

Methods: ALI was induced by cecal ligation and puncture surgery in 66 Wistar rats. After $48 \mathrm{~h}$, animals were anesthetized, mechanically ventilated and randomly assigned to 3 volemic status ( $n=22 / g r o u p): 1$ ) hypovolemia

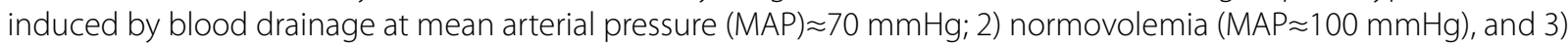
hypervolemia with colloid administration to achieve a MAP $\approx 130 \mathrm{mmHg}$. In each group, animals were further randomized to be recruited (CPAP $=40 \mathrm{~cm} \mathrm{H}_{2} \mathrm{O}$ for $40 \mathrm{~s}$ ) or not (NR) ( $n=11 /$ group), followed by $1 \mathrm{~h}$ of protective mechanical ventilation. Echocardiography, arterial blood gases, static lung elastance (Est,L), histology (light and electron microscopy), lung wet-to-dry (W/D) ratio, interleukin (IL)-6, IL-1 $\beta$, caspase-3, type III procollagen (PCIII), intercellular adhesion molecule-1 (ICAM-1), and vascular cell adhesion molecule-1 (VCAM-1) mRNA expressions in lung tissue, as well as lung and distal organ epithelial cell apoptosis were analyzed.
\end{abstract}

Results: We observed that: 1) hypervolemia increased lung W/D ratio with impairment of oxygenation and Est,L, and was associated with alveolar and endothelial cell damage and increased IL-6, VCAM-1, and ICAM-1 mRNA expressions; and 2) RM reduced alveolar collapse independent of volemic status. In hypervolemic animals, RM improved oxygenation above the levels observed with the use of positive-end expiratory pressure (PEEP), but increased lung injury and led to higher inflammatory and fibrogenetic responses.

Conclusions: Volemic status should be taken into account during RMs, since in this sepsis-induced ALI model hypervolemia promoted and potentiated lung injury compared to hypo- and normovolemia.

\section{Introduction}

Recent studies have demonstrated that low tidal volume $\left(\mathrm{V}_{\mathrm{T}}=6 \mathrm{ml} / \mathrm{kg}\right)$ significantly reduces morbidity and mortality in patients with acute lung injury/acute respiratory distress syndrome (ALI/ARDS) [1]. Such strategy

\footnotetext{
*Correspondence: prmrocco@gmail.com

${ }^{1}$ Laboratory of Pulmonary Investigation, Carlos Chagas Filho Institute of Biophysics, Federal University of Rio de Janeiro, Av. Carlos Chagas Filho, s/n, Rio de Janeiro, 21949-902, Brazil

Full list of author information is available at the end of the article
}

requires the use of moderate-to-high positive end-expiratory pressure (PEEP) and may be combined with recruitment maneuvers (RMs) [2,3]. Although the use of RMs and high PEEP is not routinely recommended, they seem effective at improving oxygenation with minor adverse effects and should be considered for use on an individualized basis in patients with ALI/ARDS who have lifethreatening hypoxemia [4]. Additionally, RMs associated with higher PEEP have been shown to reduce hypoxemiarelated deaths and can be used as rescue therapies in ALI/ 
ARDS patients [3]. However, RMs may also exacerbate epithelial [5-9] and endothelial [10] damage, increasing alveolar capillary permeability [8]. Furthermore, transient increase in intrathoracic pressure during RMs may lead to hemodynamic instability [11] and distal organ injury [12]. Despite these potential deleterious effects, RMs have been recognized as effective for improving oxygenation, at least transiently [4] and even reducing the need for rescue therapies in severe hypoxemia [3]. To minimize hemodynamic instability associated with RMs, the use of fluids has been described [13]. However, fluid management itself may have an impact on lung and distal organ injury in ALI/ARDS $[14,15]$. Although fluid restriction may cause distal organ damage [14], hypervolemia has been associated with increased lung injury $[16,17]$.

RMs seem to be more effective in extrapulmonary ALI/ ARDS [9], caused mainly by sepsis [18], than in pulmonary ALI/ARDS. Nevertheless, the maintenance of adequate volemic status is particularly challenging in sepsis. As the interaction between volemic status and RMs is not well established, we hypothesized that volemic status would potentiate possible deleterious effects of RMs on lung and distal organs in a model of extrapulmonary lung injury induced by sepsis. Therefore, we compared the effects of RMs in the presence of hypovolemia, normovolemia, and hypervolemia on arterial blood gases, static lung elastance (Est,L), histology (light and electron microscopy), lung wet-to-dry (W/D) ratio, IL-6, IL-1 $\beta$, caspase-3, type III procollagen (PCIII), intercellular adhesion molecule 1 (ICAM-1), and vascular cell adhesion molecule 1 (VCAM-1) mRNA expressions in lung tissue, as well as lung and distal organ epithelial cell apoptosis in an experimental model of sepsis-induced ALI.

\section{Materials and methods}

\section{Animal preparation and experimental protocol}

This study was approved by the Ethics Committee of the Health Sciences Center, Federal University of Rio de Janeiro. All animals received humane care in compliance with the Principles of Laboratory Animal Care formulated by the National Society for Medical Research and the Guide for the Care and Use of Laboratory Animals prepared by the National Academy of Sciences, USA.

Sixty-six adult male Wistar rats (270 to $300 \mathrm{~g}$ ) were kept under specific pathogen-free conditions in the animal care facility at the Laboratory of Pulmonary Investigation, Federal University of Rio de Janeiro. In 36 rats, Est,L, histology, and molecular biology were analyzed. The remaining 30 rats were used to evaluate lung W/D ratio. Animals were fasted for 16 hours before the surgical procedure. Following that, sepsis was induced by cecal ligation and puncture (CLP) as described in previous studies [19]. Briefly, animals were anesthetized with sevoflurane and a midline laparotomy ( $2 \mathrm{~cm}$ incision) was performed.
The cecum was carefully isolated to avoid damage to blood vessels, and a 3.0 cotton ligature was placed below the ileocecal valve to prevent bowel obstruction. Finally, the cecum was punctured twice with an 18 gauge needle [20] and animals recovered from anesthesia. Soon after surgery, each rat received a subcutaneous injection of 1 $\mathrm{ml}$ of warm $\left(37^{\circ} \mathrm{C}\right)$ normal saline with tramadol hydrochloride $(20 \mu \mathrm{g} / \mathrm{g}$ body weight).

Figure 1 depicts the time-course of interventions. Forty-eight hours after surgery, rats were sedated (diazepam $5 \mathrm{mg}$ intraperitoneally), anesthetized (thiopental sodium $20 \mathrm{mg} / \mathrm{kg}$ intraperitoneally), tracheotomized, and a polyethylene catheter (PE-10; SCIREQ, Montreal, Canada) was introduced into the carotid artery for blood sampling and monitoring of mean arterial pressure (MAP). The animals were then paralyzed (vecuronium bromide $2 \mathrm{mg} / \mathrm{kg}$, intravenously) and mechanically ventilated (Servo i, MAQUET, Switzerland) with the following parameters: $V_{T}=6 \mathrm{ml} / \mathrm{kg}$, respiratory rate $(R R)=80$ breaths $/ \mathrm{min}$, inspiratory to expiratory ratio $=1: 2$, fraction of inspired oxygen $\left(\mathrm{FiO}_{2}\right)=1.0$, and PEEP equal to 0 $\mathrm{cmH}_{2} \mathrm{O}$ (zero end-expiratory pressure (ZEEP)). Blood $(300 \mu \mathrm{l})$ was drawn into a heparinized syringe for measurement of arterial oxygen partial pressure $\left(\mathrm{PaO}_{2}\right)$, arterial carbon dioxide partial pressure $\left(\mathrm{PaCO}_{2}\right)$ and arterial pH (pHa) (i-STAT, Abbott Laboratories, North Chicago, IL, USA) (BASELINE-ZEEP). Afterwards, mechanical ventilation was set according to the following parameters: $\mathrm{V}_{\mathrm{T}}=6 \mathrm{ml} / \mathrm{kg}, \mathrm{RR}=80 \mathrm{bpm}, \mathrm{PEEP}=5 \mathrm{cmH}_{2} \mathrm{O}$, and $\mathrm{FiO}_{2}=$ 0.3 (Figure 1). Est,L was then measured (BASELINE) and the animals were randomly assigned to one of the following groups: 1) hypovolemia (HYPO); 2) normovolemia (NORMO), and 3) hypervolemia (HYPER). Hypovolemia was induced by blood drainage in order to achieve a MAP of about $70 \mathrm{mmHg}$. Normovolemia was maintained at a MAP of about $100 \mathrm{mmHg}$. Hypervolemia was obtained with colloid administration (Gelafundin; B. Braun, Melsungen, Germany) at an infusion rate of $2 \mathrm{ml} / \mathrm{kg} / \mathrm{min}$ to achieve a MAP of about $130 \mathrm{mmHg}$. Following that, the colloid infusion rate was reduced to $1 \mathrm{ml} / \mathrm{kg} / \mathrm{min}$ in order to maintain a constant MAP. Depth of anesthesia was similar in all animals and a comparable amount of sedative and anesthetic drugs were given in all groups. After achieving volemic status, animals were further randomized to be recruited, with a single RM consisting of continuous positive airway pressure (CPAP) of $40 \mathrm{cmH}_{2} \mathrm{O}$ for 40 seconds (RM-CPAP), or not (NR) ( $\mathrm{n}=6$ per group; Figure 1). After one hour of mechanical ventilation (END), Est, $\mathrm{L}$ was measured. $\mathrm{FiO}_{2}$ was then increased to 1.0, and after five minutes arterial blood gases were analyzed (END). Finally, the animals were euthanized and lungs, kidney, liver and small intestine were prepared for histology. IL-6, IL-1 $\beta$, caspase-3, and PCIII mRNA 


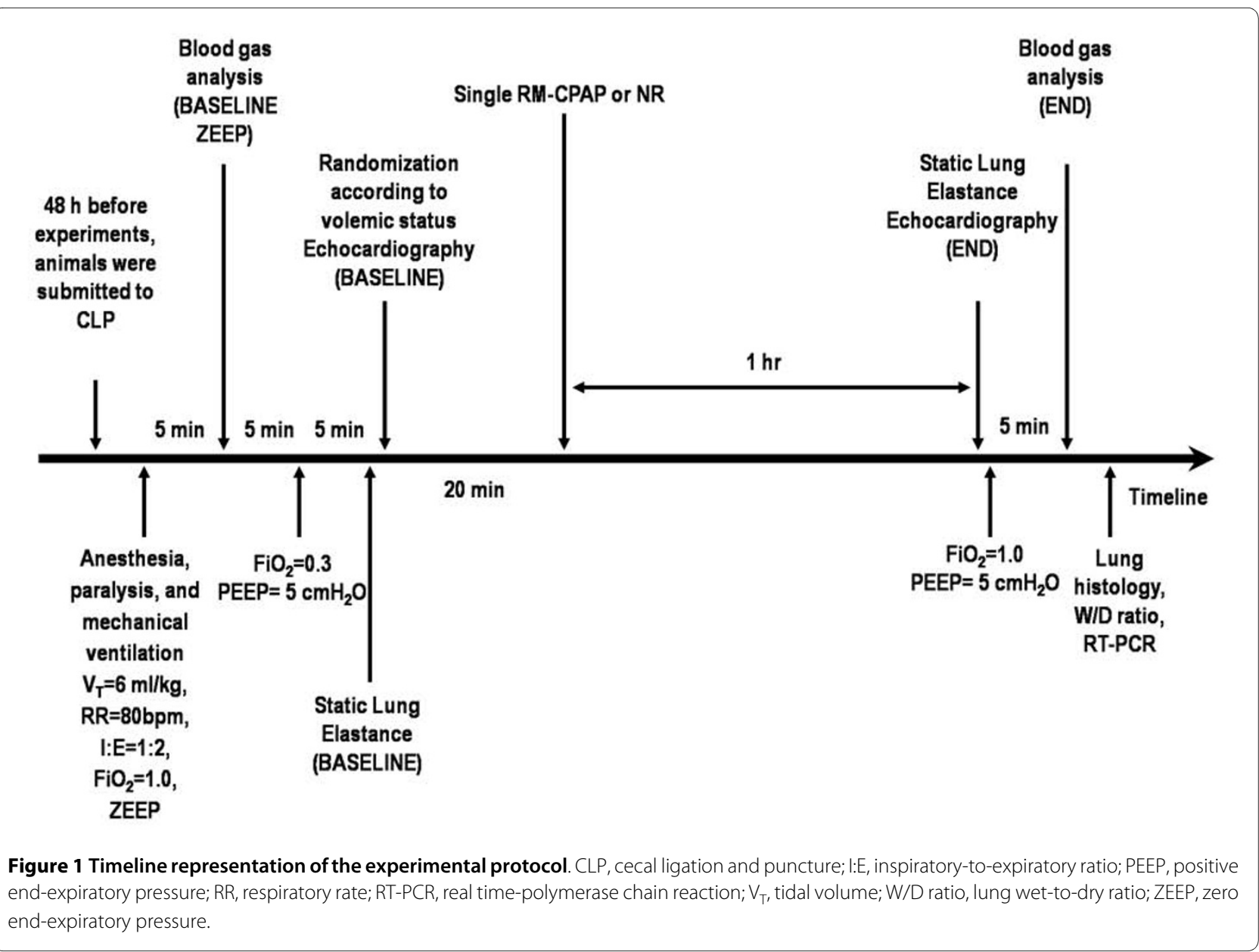

expressions were measured in lung tissue. The experiments took no longer than 80 minutes.

\section{Respiratory parameters}

Airflow, airway and esophageal pressures were measured $[9,21]$. Changes in esophageal pressure, which reflect chest wall pressure, were measured with a water-filled catheter (PE205) with side holes at the tip connected to a SCIREQ differential pressure transducer (SC-24, Montreal, Canada). Before animals were paralyzed, the catheter was passed into the stomach, slowly returned into the esophagus, and its proper positioning was assessed using the 'occlusion test' [22,23]. Transpulmonary pressure was calculated by the difference between airway and esophageal pressures [9]. All signals were filtered $(100 \mathrm{~Hz})$, amplified in a four-channel conditioner (SC-24, SCIREQ, Montreal, Quebec, Canada), sampled at $200 \mathrm{~Hz}$ with a 12-bit analogue-to-digital converter (DT2801A, Data Translation, Marlboro, MA, USA) and continuously recorded throughout the experiment by a personal computer. To calculate Est,L, airways were occluded at endinspiration until a transpulmonary plateau pressure was reached (at the end of five seconds), after which this value was divided by $\mathrm{V}_{\mathrm{T}}[9,21]$. All data were analyzed using ANADAT data analysis software (RHT-InfoData, Inc., Montreal, Quebec, Canada).

\section{Echocardiography}

Volemic status and cardiac function were assessed by an echocardiograph equipped with a $10 \mathrm{MHz}$ mechanical transducer (Esaote model, CarisPlus, Firenze, Italy). Images were obtained from the subcostal and parasternal views. Short-axis B-dimensional views of the left ventricle were acquired at the level of the papillary muscles to obtain the M-mode image. The inferior vena cava (IVC) and right atrium (RA) diameters were measured from the subcostal approach. Cardiac output, stroke volume, and ejection fraction were obtained from the B-mode according to Simpson's method [24].

\section{Light microscopy}

A laparotomy was performed immediately after determination of lung mechanics and heparin (1,000 IU) was intravenously injected in the vena cava. The trachea was clamped at end-expiration $\left(\mathrm{PEEP}=5 \mathrm{cmH}_{2} 0\right)$, and the abdominal aorta and vena cava were sectioned, yielding a 
massive hemorrhage that quickly killed the animals. Right lung, kidney, liver, and small intestine were then removed, fixed in 3\% buffered formaldehyde and paraffin-embedded. Four- $\mu \mathrm{m}$-thick slices were cut and stained with $H \& E$.

Lung morphometric analysis was performed using an integrating eyepiece with a coherent system consisting of a grid with 100 points and 50 lines (known length) coupled to a conventional light microscope (Olympus BX51, Olympus Latin America-Inc., São Paulo, Brazil). The volume fraction of the lung occupied by collapsed alveoli or normal pulmonary areas or hyperinflated structures (alveolar ducts, alveolar sacs, or alveoli, all wider than 120 $\mu \mathrm{m})$ was determined by the point-counting technique [25] at a magnification of $\times 200$ across 10 random, noncoincident microscopic fields [26].

\section{Transmission electron microscopy}

Three slices measuring $2 \times 2 \times 2 \mathrm{~mm}$ were cut from three different segments of the left lung and fixed (2.5\% glutaraldehyde and phosphate buffer $0.1 \mathrm{M}(\mathrm{pH}=7.4))$ for electron microscopy (JEOL 1010 Transmission Electron Microscope, Tokyo, Japan) analysis. For each electron microscopy image (15 per animal), the following structural damages were analyzed: a) alveolar capillary membrane, b) type II epithelial cells, and c) endothelial cells. Pathologic findings were graded according to a five-point semi-quantitative severity-based scoring system as: $0=$ normal lung parenchyma, 1 = changes in 1 to $25 \%, 2=$ changes in 26 to $50 \%, 3=$ changes in 51 to $75 \%$, and $4=$ changes in 76 to $100 \%$ of examined tissue $[9,21]$.

\section{Apoptosis assay of lung, kidney, liver and small intestine villi}

Terminal deoxynucleotidyl transferase biotin-dUTP nick end labeling (TUNEL) staining was used in a blinded fashion by two pathologists to assay cellular apoptosis. Apoptotic cells were detected using In Situ Cell Death Detection Kit, Fluorescin (Boehringer, Mannheim, Frankfurt, Germany). The nuclei without DNA fragmentation stained blue as a result of counterstaining with hematoxylin [20]. Ten fields per section from the regions with apoptotic cells were examined at a magnification of $\times 400$. A five-point semi-quantitative severity-based scoring system was used to assess the degree of apoptosis, graded as: $0=$ normal lung parenchyma; $1=1-25 \% ; 2=26$ to $50 \% ; 3=51$ to $75 \%$; and $4=76$ to $100 \%$ of examined tissue.

\section{IL-6, IL-1 $\beta$, caspase-3, PCIII, VCAM-1, and ICAM-1 mRNA expressions}

Quantitative real-time RT-PCR was performed to measure the expression of IL- 6 , IL- $1 \beta$, caspase-3, PCIII, VCAM, and ICAM genes. Central slices of left lung were cut, collected in cryotubes, quick-frozen by immersion in liquid nitrogen and stored at $-80^{\circ} \mathrm{C}$. Total RNA was extracted from the frozen tissues using Trizol reagent (Invitrogen, Carlsbad, CA, USA) according to manufacturer's recommendations. RNA concentration was measured by spectrophotometry in Nanodrop ND-1000 (Thermo Fisher Scientific, Wilmington, DE, USA). Firststrand cDNA was synthesized from total RNA using MMLV Reverse Transcriptase Kit (Invitrogen, Carlsbad, CA, USA). PCR primers for target gene were purchased (Invitrogen, Carlsbad, CA, USA). The following primers were used: IL-1 $\beta$ (sense 5 '-CTA TGT CTT GCC CGT GGA G-3', and antisense 5'-CAT CAT CCC ACG AGT CAC A-3'); IL- 6 (sense 5'-CTC CGC AAG AGA CTT CCA G-3' and antisense 5'-CTC CTC TCC GGA CTT GTG A-3'); PCIII (sense 5'-ACC TGG ACC ACA AGG ACA C-3' and antisense 5'-TGG ACC CAT TTC ACC TTT C-3'); caspase-3 (sense 5'-GGC CGA CTT CCT GTA TGC-3' and antisense 5'-GCG CAA AGT GAC TGG ATG-3'); VCAM-1 (sense 5'-TGC ACG GTC CCT AAT GTG TA-3' and antisense 5'-TGC CAA TTT CCT CCC TTA AA-3'); ICAM-1 (sense 5'-CTT CCG ACT AGG GTC CTG AA-3' and antisense 5'-CTT CAG AGG CAG GAA ACA GG-3'); and glyceraldehyde-3-phosphate dehydrogenase (GAPDH; sense 5'-GGT GAA GGT CGG TGTG AAC- 3' and antisense 5'-CGT TGA TGG CAA CAA TGT C-3'). Relative mRNA levels were measured with a SYBR green detection system using ABI 7500 Real-Time PCR (Applied Biosystems, Foster City, CA, USA). All samples were measured in triplicate. The relative expression of each gene was calculated as a ratio compared with the reference gene, GAPDH and expressed as fold change relative to NORMO-NR.

\section{Lung wet-to-dry ratio}

$\mathrm{W} / \mathrm{D}$ ratio was determined in the right lung as previously described [27]. Briefly, the right lung was separated, weighed (wet weight) and then dried in a microwave at low power $(200 \mathrm{~W})$ for five minutes. The drying process was repeated until the difference between the two consecutive lung weight measurements was less than $0.002 \mathrm{~g}$. The last weight measurement represented the dry weight.

\section{Statistical analysis}

Normality of data was tested using the KolmogorovSmirnov test with Lilliefors' correction, while the Levene median test was used to evaluate the homogeneity of variances. If both conditions were satisfied, one-way analysis of variance (ANOVA) for repeated measures was used to compare the time course of MAP, IVC and RA dimensions. To compare arterial blood gases, Est,L, and echocardiographic data at BASELINE and after one hour of mechanical ventilation (END), the paired $t$-test was used. Lung mechanics (END) and morphometry, echocardiographic data (END), arterial blood gases 
(END), W/D ratio, and inflammatory and fibrogenic mediators were analyzed using two-way ANOVA followed by Tukey's test. To compare non-parametric data, two-way ANOVA on ranks followed by Dunn's post-hoc test was selected. The relations between functional and morphological data were investigated with the Spearman correlation test. Parametric data were expressed as mean \pm standard error of the mean, while non-parametric data were expressed as median (interquartile range). All tests were performed using the SigmaStat 3.1 statistical software package (Jandel Corporation, San Raphael, CA, USA), and statistical significance was established as $P<$ 0.05 .

\section{Results}

The present CLP model of sepsis resulted in a survival rate of approximately $60 \%$ at 48 hours. No animals died during the investigation period.

In the HYPO, NORMO and HYPER groups, MAP was stabilized at $70 \pm 10,100 \pm 10$, and $130 \pm 10 \mathrm{mmHg}$, respectively (Table 1 ). The smallest RA and IVC diameters were observed in the HYPO and the largest in the HYPER groups (Table 1). Stroke volume and cardiac output, as well as ejection fraction were similar at BASELINE in all groups (Table 2). In the HYPER group, stroke volume, cardiac output, and ejection fraction were increased compared with the NORMO and HYPO groups, with no significant changes after RM (Table 2).

Table 3 shows arterial blood gases and lung mechanics in the three groups. $\mathrm{PaO}_{2}, \mathrm{PaCO}_{2}$, and $\mathrm{pHa}$ were comparable at BASELINE ZEEP in all groups. At END, $\mathrm{PaO}_{2}$ was lower in HYPER compared with the HYPO and NORMO groups when RMs were not applied. When RMs were applied, $\mathrm{PaO}_{2}$ was higher in NORMO compared with the HYPER group. In HYPER group, $\mathrm{PaO}_{2}$ was higher in RM-CPAP compared with the NR subgroup, while no differences in $\mathrm{PaO}_{2}$ were found between RMCPAP and NR in HYPO and NORMO groups. $\mathrm{PaCO}_{2}$ and pHa did not change significantly in either NR or RMCPAP regardless of volemic status. Est,L was similar at BASELINE in all groups. At END, Est,L was significantly increased in HYPER compared with HYPO and NORMO groups when RMs were not applied. Est,L was reduced in both HYPO and HYPER groups when lungs were recruited. However, Est,L did not change in NORMO group after RMs.

The fraction of alveolar collapse was higher in HYPER (42\%) compared with HYPO (27\%) and NORMO (28\%) groups. RMs decreased alveolar collapse independently of volemic status; nevertheless, alveolar collapse was more frequent in HYPER (26\%) than NORMO (17\%) and HYPO (12\%) groups. Hyperinflated areas were not detected in any group (Figure 2).
Lung W/D ratio was higher in HYPER than in HYPO and NORMO groups. Furthermore, lung W/D ratio was increased in NORMO and HYPER groups after RMs (Figure 3 ).

In the NR groups, lung W/D ratio was positively correlated with the fraction area of alveolar collapse $(r=0.906$, $P<0.001)$ and Est, $\mathrm{L}(r=0.695, P<0.001)$, and negatively correlated with $\mathrm{PaO}_{2}(r=-0.752, P<0.001)$. Furthermore, the fraction area of alveolar collapse was positively correlated with Est, $\mathrm{L}(r=0.681, P<0.001)$ and negatively correlated with $\mathrm{PaO}_{2}(r=-0.798, P<0.001)$. In the RM-CPAP groups, lung $\mathrm{W} / \mathrm{D}$ ratio was positively correlated with the fraction area of alveolar collapse $(r=0.862, P<0.001)$ and Est, $\mathrm{L}(r=0.704, P<0.001)$, while there was no correlation with $\mathrm{PaO}_{2}$. In addition, the fraction area of alveolar collapse was positively correlated with Est, $\mathrm{L}(r=0.803, P<$ 0.001), but not with $\mathrm{PaO}_{2}$.

Figure 4 depicts typical electron microscopy findings in each group. ALI animals showed injury of cytoplasmic organelles in type II pneumocytes (PII) and aberrant lamellar bodies, as well as endothelial cell and neutrophil apoptosis. Detachment of the alveolar-capillary membrane and endothelial cell injury were more pronounced in HYPER compared with HYPO and NORMO groups (Table 4). When RMs were applied, hypervolemia resulted in increased detachment of the alveolar capillary membrane, as well as injury of PII and endothelium, compared with normovolemia.

Hypervolemia did not increase apoptosis of lung, kidney, liver, and small intestine villous cells (Table 5). In the HYPER group, RMs led to increased TUNEL positive cells (Table 5 and Figure 5), but not of kidney, liver, and small intestine villous cells.

In NR groups, IL-6, VCAM-1, and ICAM-1 mRNA expressions were higher in HYPER compared with the HYPO and NORMO groups. VCAM-1 and ICAM-1 expressions were also higher in HYPO compared with NORMO, reduced after RMs in HYPO, but augmented in NORMO group. In HYPER group, VCAM-1 expression rose after RMs but ICAM-1 remained unaltered. IL-6, IL$1 \beta$, PCIII, and caspase- 3 mRNA expressions increased after RMs in HYPER group, but not in NORMO and HYPO groups (Figure 6).

\section{Discussion}

In the present study, we examined the effects of RMs in an experimental sepsis-induced ALI model at different levels of MAP and volemia. We found that: 1) hypervolemia increased lung W/D ratio and alveolar collapse leading to an impairment in oxygenation and Est,L. Furthermore, hypervolemia was associated with alveolar and endothelium damage as well as increased IL-6, VCAM-1 and ICAM-1 mRNA expressions in lung tissue; 2) RMs 
Table 1: Mean arterial pressure and inferior vena cava and right atrium dimensions

\begin{tabular}{|c|c|c|c|c|c|c|c|c|}
\hline & & & BASELINE & $5 \mathrm{~min}$ & $10 \mathrm{~min}$ & $15 \mathrm{~min}$ & $20 \mathrm{~min}$ & $80 \mathrm{~min}$ \\
\hline \multirow[t]{6}{*}{ MAP $(\mathrm{mmHg})$} & HYPO & NR & $110 \pm 6$ & $107 \pm 5$ & $77 \pm 4^{*}$ & $70 \pm 3^{*}$ & $67 \pm 3^{*}$ & $62 \pm 3^{*}$ \\
\hline & & RM-CPAP & $110 \pm 2$ & $97 \pm 2$ & $76 \pm 2^{*}$ & $71 \pm 1^{*}$ & $65 \pm 2^{*}$ & $63 \pm 1^{*}$ \\
\hline & NORMO & NR & $104 \pm 8$ & $101 \pm 6$ & $100 \pm 6^{* *}$ & $103 \pm 6^{* *}$ & $100 \pm 4^{* *}$ & $97 \pm 4^{* *}$ \\
\hline & & RM-CPAP & $103 \pm 2$ & $103 \pm 2$ & $100 \pm 2 \ddagger$ & $105 \pm 3 \ddagger$ & $96 \pm 3 \neq$ & $95 \pm 2 \neq$ \\
\hline & HYPER & NR & $106 \pm 3$ & $128 \pm 2 * * * \#$ & $130 \pm 2 * * * \#$ & $131 \pm 3^{* * * \#}$ & $131 \pm 2^{* * *} \#$ & $126 \pm 2^{* * *} \#$ \\
\hline & & RM-CPAP & $103 \pm 2$ & $126 \pm 5^{*} \neq \S$ & $129 \pm 4^{*} \ddagger \S$ & $128 \pm 4^{*} \ddagger \S$ & $124 \pm 2^{*} \neq \S$ & $117 \pm 5^{*} \ddagger \S$ \\
\hline \multirow{6}{*}{$\begin{array}{c}\text { IVC } \\
(\mathrm{mm})\end{array}$} & HYPO & $N R$ & $1.6 \pm 0.2$ & $1.5 \pm 0.1$ & $1.2 \pm 0.1^{*}$ & $1.0 \pm 0.1^{*}$ & $1.0 \pm 0.1^{*}$ & $0.9 \pm 0.0^{*}$ \\
\hline & & RM-CPAP & $1.6 \pm 0.2$ & $1.4 \pm 0.1$ & $1.1 \pm 0.1^{*}$ & $0.9 \pm 0.1^{*}$ & $0.8 \pm 0.0^{*}$ & $0.7 \pm 0.0^{*}$ \\
\hline & NORMO & NR & $1.6 \pm 0.1$ & $1.7 \pm 0.1$ & $1.6 \pm 0.1$ & $1.7 \pm 0.0^{* *}$ & $1.7 \pm 0.0^{* *}$ & $1.5 \pm 0.0^{* *}$ \\
\hline & & RM-CPAP & $1.5 \pm 0.0$ & $1.5 \pm 0.0$ & $1.4 \pm 0.0$ & $1.6 \pm 0.0 \neq$ & $1.6 \pm 0.0 \neq$ & $1.4 \pm 0.0 \neq$ \\
\hline & HYPER & NR & $1.4 \pm 0.0$ & $2.3 \pm 0.2^{* * * \#}$ & $2.6 \pm 0.1^{* * *} \#$ & $2.5 \pm 0.3^{* * * \#}$ & $2.6 \pm 0.3^{* * *} \#$ & $2.6 \pm 0.1^{* * *} \#$ \\
\hline & & RM-CPAP & $1.4 \pm 0.0$ & $2.1 \pm 0.2^{*} \neq \S$ & $2.5 \pm 0.1^{*} \neq \S$ & $2.6 \pm 0.1^{*} \neq \S$ & $2.6 \pm 0.2^{*} \neq \S$ & $2.4 \pm 0.2^{*} \neq \S$ \\
\hline \multirow{6}{*}{$\begin{array}{c}\mathrm{RA} \\
(\mathrm{mm})\end{array}$} & HYPO & NR & $4.0 \pm 0.4$ & $3.9 \pm 0.6$ & $3.8 \pm 0.4$ & $2.8 \pm 0.2^{*}$ & $2.3 \pm 0.3^{*}$ & $2.7 \pm 0.2^{*}$ \\
\hline & & RM-CPAP & $4.2 \pm 0.1$ & $3.4 \pm 0.1$ & $3.1 \pm 0.0^{*}$ & $2.9 \pm 0.0^{*}$ & $2.5 \pm 0.2^{*}$ & $3.0 \pm 0.0^{*}$ \\
\hline & NORMO & NR & $3.5 \pm 0.0$ & $3.5 \pm 0.0$ & $3.7 \pm 0.0$ & $3.5 \pm 0.0^{* *}$ & $3.6 \pm 0.0^{* *}$ & $3.3 \pm 0.0^{* *}$ \\
\hline & & RM-CPAP & $3.6 \pm 0.1$ & $3.5 \pm 0.1$ & $3.6 \pm 0.0$ & $3.5 \pm 0.0 \neq$ & $3.6 \pm 0.0 \neq$ & $3.5 \pm 0.1 \neq$ \\
\hline & HYPER & NR & $3.9 \pm 0.1$ & $4.8 \pm 0.5$ & $6.1 \pm 0.4^{* * * \#}$ & $6.5 \pm 0.4^{* * * \#}$ & $7.1 \pm 0.4^{* * *} \#$ & $7.4 \pm 0.0^{* * *} \#$ \\
\hline & & RM-CPAP & $4.1 \pm 0.1$ & $6.5 \pm 0.5^{*} \neq \S$ & $7.2 \pm 0.3^{*} \neq \S$ & $7.2 \pm 0.3^{*} \neq \S$ & $7.3 \pm 0.3^{*} \neq \S$ & $7.1 \pm 0.2^{*} \ddagger \S$ \\
\hline
\end{tabular}

Mean arterial pressure (MAP), and inferior vena cava (IVC) and right atrium (RA) dimensions at BASELINE, during the induction of hyper or hypovolemia (BASELINE until $20 \mathrm{~min}$ ), and at the end of the experiment $(80 \mathrm{~min})$. Animals were randomly assigned to hypovolemia (HYPO), normovolemia (NORMO) or hypervolemia (HYPER) with recruitment maneuver (RM-CPAP) or not (NR). Values are shown as mean \pm standard error of the mean of six rats in each group. *Significantly different from BASELINE $(P<0.05)$. †Significantly different from NR $(P<0.05)$. ${ }^{*}$ Significantly different from HYPO-NR $(P<0.05)$. ‡ Significantly different from HYPO-RM-CPAP $(P<0.05)$. \#Significantly different from NORMO-NR $(P<0.05)$. $\S$ Significantly different from NORMO-RM-CPAP $(P<0.05)$.

reduced alveolar collapse regardless of volemic status. In hypervolemic animals, RMs improved oxygenation above the levels observed with the use of PEEP, but were associated with increased lung injury and higher inflammatory and fibrogenic responses; and 3) volemic status associated or not with RMs had no effects on distal organ injury.

\section{Methodological aspects}

To our knowledge, this is the first study investigating the combined effects of RMs and volemic status in sepsisinduced ALI. We used a CLP model of sepsis because it is reproducible and leads to organ injury that is comparable with that observed in human surgical sepsis [28,29].

Volemic status was assessed by echocardiography. It has been shown that echocardiography provides valuable information on preload and cardiac output $[30,31]$. An inspired oxygen fraction of 0.3 was used throughout the study to minimize possible iatrogenic effects of high inspiratory oxygen concentration on the lung parenchyma [32]. To avoid possible confounding effects of ventilation/perfusion mismatch on the interpretation of the gas-exchange data, inspiratory oxygen fraction was increased to 1.0 just before arterial blood sampling [33]. 


\begin{tabular}{|c|c|c|c|c|c|c|c|}
\hline & & \multicolumn{2}{|c|}{ HYPO } & \multicolumn{2}{|c|}{ NORMO } & \multicolumn{2}{|c|}{ HYPER } \\
\hline & & NR & RM-CPAP & NR & RM-CPAP & NR & RM-CPAP \\
\hline \multirow{2}{*}{$\begin{array}{c}\text { Cardiac } \\
\text { Output }\left(\mathrm{ml}^{\mathrm{min}} \mathrm{min}^{-1}\right)\end{array}$} & BASELINE & $20 \pm 10$ & $20 \pm 10$ & $20 \pm 10$ & $20 \pm 10$ & $20 \pm 10$ & $40 \pm 10 † \S$ \\
\hline & END & $10 \pm 10$ & $10 \pm 10$ & $10 \pm 10$ & $20 \pm 10$ & $60 \pm 10^{* * * \#}$ & $60 \pm 10 \neq \S$ \\
\hline \multirow[t]{2}{*}{ Stroke volume (ml) } & BASELINE & $0.17 \pm 0.01$ & $0.13 \pm 0.01 \dagger$ & $0.13 \pm 0.01^{* *}$ & $0.13 \pm 0.01$ & $0.10 \pm 0.05^{* *}$ & $0.13 \pm 0.01$ \\
\hline & END & $0.10 \pm 0.01^{*}$ & $0.10 \pm 0.01$ & $0.10 \pm 0.01$ & $0.13 \pm 0.01$ & $0.33 \pm 0.01^{* *} \#$ & $0.26 \pm 0.01^{*} \dagger \ddagger \S$ \\
\hline \multirow{2}{*}{$\begin{array}{c}\text { Ejection } \\
\text { fraction (\%) }\end{array}$} & BASELINE & $74 \pm 1$ & $73 \pm 3$ & $78 \pm 4$ & $74 \pm 4$ & $74 \pm 1$ & $68 \pm 7$ \\
\hline & END & $63 \pm 4^{*}$ & $65 \pm 1^{*}$ & $71 \pm 1$ & $73 \pm 1 \neq$ & $86 \pm 3^{* * *} \#$ & $88 \pm 3^{*} \neq \S$ \\
\hline
\end{tabular}

Echocardiographic data measured at BASELINE and after one hour of mechanical ventilation (END). Animals were randomly assigned to hypovolemia (HYPO), normovolemia (NORMO) or hypervolemia (HYPER) with recruitment maneuver (RM-CPAP) or not (NR). Values are mean \pm standard error of the mean of six rats in each group. *Significantly different from BASELINE $(P<0.05)$. †Significantly different from NR $(P<0.05)$. ${ }^{*}$ Significantly different from HYPO-NR $(P<0.05)$. ‡Significantly different from HYPO-RM-CPAP $(P<0.05)$. \#Significantly different from NORMONR $(P<0.05)$. §Significantly different from NORMO-RM-CPAP $(P<0.05)$.

All animals underwent protective mechanical ventilation to minimize possible interactions between conventional mechanical ventilation, volemic status, and RMs.

The mRNA expressions of IL- 6 and IL- $1 \beta$ in lung tissue were determined due to the role of these markers in the pathogenesis of sepsis and ventilator-induced lung injury (VILI) [34]. Although IL-6 has been implicated in the triggering process of sepsis and correlates with its severity [35], IL-1 $\beta$ has been associated with the degree of VILI [32]. On the other hand, mRNA expression of PCIII was

Table 3: Arterial blood gases and static lung elastance

\begin{tabular}{|c|c|c|c|c|c|c|c|}
\hline & & \multicolumn{2}{|c|}{ HYPO } & \multicolumn{2}{|c|}{ NORMO } & \multicolumn{2}{|c|}{ HYPER } \\
\hline & & NR & RM-CPAP & NR & RM-CPAP & NR & RM-CPAP \\
\hline $\begin{array}{c}\mathrm{PaO}_{2} \\
(\mathrm{mmHg})\end{array}$ & BASELINE ZEEP & $225 \pm 96$ & $190 \pm 38$ & $164 \pm 40$ & $228 \pm 114$ & $147 \pm 64$ & $212 \pm 88$ \\
\hline \multirow[t]{2}{*}{$\mathrm{PaCO}_{2}(\mathrm{mmHg})$} & BASELINE ZEEP & $31 \pm 2$ & $30 \pm 7$ & $34 \pm 4$ & $37 \pm 5$ & $35 \pm 3$ & $37 \pm 7$ \\
\hline & END & $34 \pm 6$ & $32 \pm 5$ & $28 \pm 9$ & $37 \pm 3$ & $39 \pm 12$ & $35 \pm 11$ \\
\hline \multirow[t]{2}{*}{$\mathrm{pHa}$} & BASELINE ZEEP & $7.30 \pm 0.10$ & $7.23 \pm 0.01$ & $7.27 \pm 0.10$ & $7.25 \pm 0.10$ & $7.24 \pm 0.10$ & $7.22 \pm 0.01$ \\
\hline & END & $7.11 \pm 0.10$ & $7.13 \pm 0.01$ & $7.19 \pm 0.10$ & $7.21 \pm 0.10$ & $7.23 \pm 0.10$ & $7.22 \pm 0.01$ \\
\hline \multirow[t]{2}{*}{ Est,L $\left(\mathrm{cmH}_{2} \mathrm{O} \cdot \mathrm{ml}^{-1}\right)$} & BASELINE & $3.4 \pm 0.3$ & $3.2 \pm 0.5$ & $3.0 \pm 0.3$ & $3.1 \pm 0.3$ & $3.3 \pm 0.5$ & $3.3 \pm 0.5$ \\
\hline & END & $3.1 \pm 0.4$ & $1.2 \pm 0.1^{*} \dagger$ & $2.6 \pm 0.1$ & $2.5 \pm 0.4 \neq$ & $4.1 \pm 0.7 \# \neq$ & $2.8 \pm 0.6 \dagger$ \\
\hline
\end{tabular}

Arterial oxygen partial pressure $\left(\mathrm{PaO}_{2}, \mathrm{mmHg}\right)$, arterial carbon dioxide partial pressure $\left(\mathrm{PaCO}_{2}\right)$, and arterial pH (pHa) measured at BASELINE-ZEEP and after one hour of mechanical ventilation (END). Static lung elastance (Est,L) measured at BASELINE (positive end-expiratory pressure $=5$ $\mathrm{CmH}_{2} \mathrm{O}$ ) and at END. Animals were randomly assigned to hypovolemia (HYPO), normovolemia (NORMO) or hypervolemia (HYPER) with recruitment maneuver (RM-CPAP) or not (NR). Values are mean \pm standard error of the mean of six rats in each group. *Significantly different from BASELINE $(P<0.05)$. †Significantly different from NR $(P<0.05)$. **Significantly different from HYPO-NR $(P<0.05)$. ¥Significantly different from HYPO-RM-CPAP $(P<0.05)$. \#Significantly different from NORMO-NR $(P<0.05)$. §Significantly different from NORMO-RM-CPAP $(P<0.05)$. 


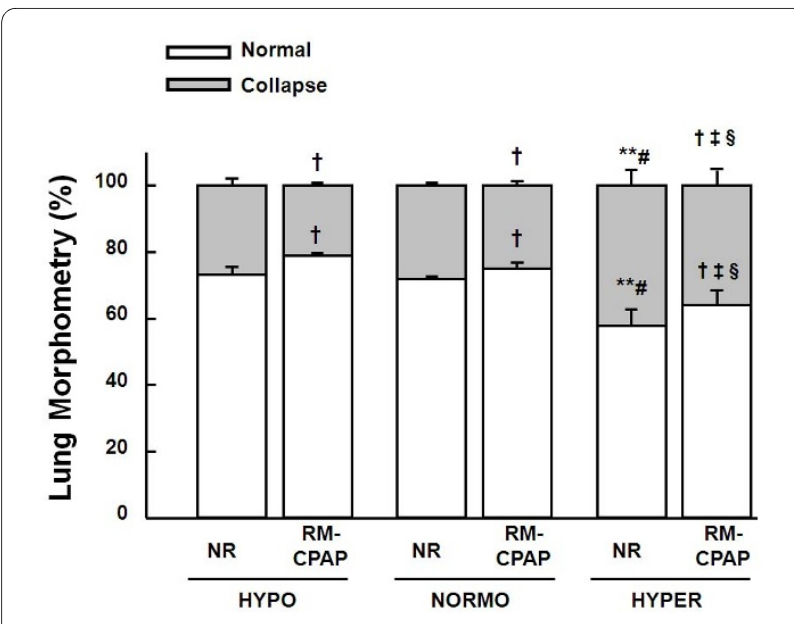

Figure 2 Volume fraction of the lung occupied by collapsed alveoli (gray) or normal pulmonary areas (white). Animals were randomly assigned to hypovolemia (HYPO), normovolemia (NORMO) or hypervolemia (HYPER) with recruitment maneuver (RM-CPAP) or not (NR). All values were computed in 10 random, noncoincident fields per rat. Values are mean \pm standard error of the mean of six animals in each group. †Significantly different from NR $(P<0.05)$. ${ }^{* *}$ Significantly different from HYPO-NR $(P<0.05)$. \#Significantly different from HYPO-RMCPAP $(P<0.05)$. \#Significantly different from NORMO-NR $(P<0.05)$. $\S$ Significantly different from NORMO-RM-CPAP $(P<0.05)$.

determined because it is the first collagen to be remodeled in the development/course of lung fibrogenesis [36], as well as being an early marker of lung parenchyma remodeling [32,37]. We also measured the levels of mRNA expression of caspase-3, because it represents a surrogate parameter for the final step of apoptosis [38].

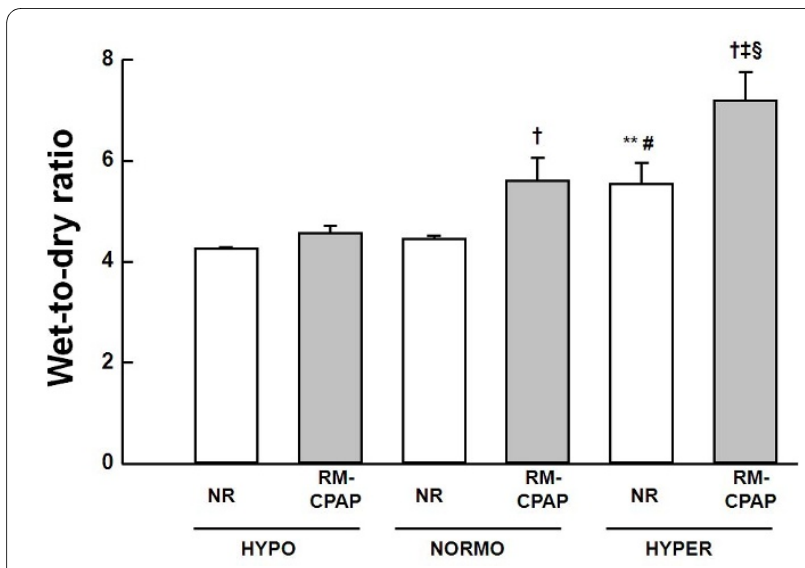

Figure 3 Wet-to-dry ratio measured after one hour of mechanical ventilation. Animals were randomly assigned to hypovolemia (HYPO), normovolemia (NORMO) or hypervolemia (HYPER) with recruitment maneuver (RM-CPAP) or not (NR). Values are mean \pm standard error of the mean of six rats in each group. TSignificantly different from NR $(P<$ 0.05). **Significantly different from HYPO-NR $(P<0.05)$. \#Significantly different from HYPO-RM-CPAP $(P<0.05)$. \#Significantly different from NORMO-NR $(P<0.05)$. §Significantly different from NORMO-RM-CPAP $(P<0.05)$.
Finally, the effects of volemic status and RM on mRNA expressions of ICAM-1 and VCAM-1 were determined because these adhesion molecules are involved in the accumulation of neutrophils in the lung tissue, playing a crucial role in the pathogenesis of VILI [39].

\section{Effects of volemia on lung and distal organ injury}

In severe sepsis aggressive fluid resuscitation is recommended [40]. However, in ALI/ARDS the optimal fluid management protocol is yet to be established. Conservative management of ALI/ARDS prescribes that fluid intake be restricted in an attempt to decrease pulmonary edema, shorten the duration of mechanical ventilation, and improve survival. A possible risk of this approach is a decrease in cardiac output and worsening of distal organ function, both of which are reversed with the liberal approach.

Our data show that a hypervolemic status led to increased lung, but not distal organ injury. In fact, hypervolemia was associated with a more pronounced detachment of the alveolar-capillary membrane as well as injury of endothelial cells. On the other hand, fluid restriction did not increase distal organ injury. Different mechanisms could explain the adverse effects of hypervolemia on lung injury: 1) increased hydrostatic pressures; and 2) augmented capillary blood flow and volume.

During hypervolemia, increased pulmonary edema was induced by altered permeability of the alveolar capillary membrane, which is a common finding in sepsis [41], combined with higher hydrostatic pressure. In the presence of pulmonary edema, the increase in hydrostatic pressures along the ventral-dorsal gradient promoted a reduction in normally aerated tissue, contributing to increased stress/strain and cyclic collapse/reopening [42]. Hypervolemic groups were characterized by impaired oxygenation and higher Est,L. The reduction in oxygenation can be attributed to increased edema and atelectasis. The increase in Est,L suggested higher lung stress in aerated lung areas during inflation. In addition, as the same $\mathrm{V}_{\mathrm{T}}$ was applied in all groups and hypervolemia decreased the normally aerated tissue, the strain in the hypervolemic group may be increased. However, even if stress/strain were higher, we did not observe hyperinflation probably because low $\mathrm{V}_{\mathrm{T}}$ and moderate PEEP levels were applied. In this line, cyclic collapse/reopening has also been recognized as a determinant of VILI [43].

Cardiac output, stroke volume, and ejection fraction were increased during hypervolemia. Increased pulmonary perfusion may also directly damage the lungs. In a model of VILI, Lopez-Aguilar and colleagues [44] have shown that the intensity of pulmonary perfusion contributes to the formation of pulmonary edema, adverse distribution of ventilation, and histological damage. 


\begin{tabular}{|c|c|c|c|c|c|c|}
\hline & \multicolumn{2}{|c|}{ HYPO } & \multicolumn{2}{|c|}{ NORMO } & \multicolumn{2}{|c|}{ HYPER } \\
\hline & NR & RM-CPAP & NR & RM-CPAP & NR & RM-CPAP \\
\hline Alveolar capillary membrane & $\begin{array}{c}2 \\
(2-2.5)\end{array}$ & $\begin{array}{c}2 \\
(2-3)\end{array}$ & $\begin{array}{c}2 \\
(2-2.25)\end{array}$ & $\begin{array}{c}3 \\
(2-3)\end{array}$ & $\begin{array}{c}3^{* * \#} \\
(3-3.25)\end{array}$ & $\begin{array}{c}4 \neq \S \\
(3.75-4)\end{array}$ \\
\hline Type II epithelial cell & $\begin{array}{c}2 \\
(2-2.25)\end{array}$ & $\begin{array}{c}3 \\
(2-3)\end{array}$ & $\begin{array}{c}2 \\
(2-2.25)\end{array}$ & $\begin{array}{c}3 \\
(2-3)\end{array}$ & $\begin{array}{c}3 \\
(2.75-4)\end{array}$ & $\begin{array}{c}4 \neq \S \\
(3.75-4)\end{array}$ \\
\hline Endothelial cell & $\begin{array}{c}2 \\
(1.75-2.25)\end{array}$ & $\begin{array}{c}2 \\
(2-3)\end{array}$ & $\begin{array}{c}2 \\
(2-2.25)\end{array}$ & $\begin{array}{c}3 \\
(2.75-3)\end{array}$ & $\begin{array}{l}3 * * \# \\
(3-4)\end{array}$ & $\begin{array}{c}4 \neq \S \\
(3.75-4)\end{array}$ \\
\hline $\begin{array}{l}\text { Pathologic findings were graded } \\
=\text { changes in } 1 \text { to } 25 \%, 2=26 \text { to } \\
\text { hypovolemia (HYPO), normovole } \\
\text { median }\left(25^{\text {th }} \text { percentile to } 75^{\text {th }} \text { pe }\right. \\
\text { from HYPO-RM-CPAP }(P<0.05) \text {. }\end{array}$ & $\begin{array}{l}\text { ling to a five- } \\
=51 \text { to } 75 \% \text {, } \\
\text { ORMO) or hy } \\
\text { e) of five anin } \\
\text { cantly differe }\end{array}$ & $\begin{array}{l}\text { emi-quantit } \\
=76 \text { to } 100 \% \\
\text { emia (HYPER } \\
\text { group. }{ }^{*} \text { Si } \\
\text { NORMO-NF }\end{array}$ & $\begin{array}{l}\text { severity-b } \\
\text { le examin } \\
\text { recruitm } \\
\text { antly diffe } \\
0.05) \text {. } \$ \text { Si }\end{array}$ & $\begin{array}{l}\text { coring syster } \\
\text { ue. Animals } \\
\text { aneuver (RM } \\
\text { om HYPO-NR }\end{array}$ & $\begin{array}{l}\text { normal lu } \\
\text { andomly } \\
\text { ) or not (N } \\
.05) \text {. } \neq \text { Sig } \\
\text { NORMO-R }\end{array}$ & $\begin{array}{l}\text { renchyma, } 1 \\
\text { ed to } \\
\text { lues are the } \\
\text { htly different } \\
\text { AP }(P<0.05)\end{array}$ \\
\hline
\end{tabular}

In hypervolemia, we observed an increase in IL-6 mRNA expression in lung tissue, but PCIII mRNA expression did not change, which may be explained by the absence of hyperinflation [12]. Additionally, VCAM-1 and ICAM-1 mRNA expressions were elevated in HYPER group suggesting endothelial activation due to vascular mechanical stretch.

Despite increased lung injury and activation of the inflammatory process, hypervolemia was not associated with increased distal organ injury. Furthermore, hypovolemia and normovolemia did not contribute to distal organ injury, but rather protected the lungs from further damage. Our observation supports the claim that the lungs are particularly sensitive to fluid overload [45]. Lung-borne inflammatory mediators can spill over into the circulation and promote distal organ injury. However, when protective mechanical ventilation is used, decompartmentalization of the inflammatory process is limited [46].

Interactions between recruitment maneuvers and volemia The low $\mathrm{V}_{\mathrm{T}}$ and airway pressure concept has been shown to decrease the mortality in ALI/ARDS patients [1]. Given the uncertain benefit of RMs on clinical outcomes, the routine use of RMs in ALI/ARDS patients cannot be recommended at this time. However, RMs have been shown to improve oxygenation without serious adverse events [11]. Furthermore, other papers suggested that RMs may be useful before PEEP setting, after inadvertent disconnection of the patient from the mechanical ventilator or airways aspiration [47]. Finally, RMs have been proposed to further improve respiratory function in ALI/ ARDS patients in prone position [48]. Thus, in our opin- ion, their judicious use in the clinical setting may be justified.

In our animals, RMs reduced alveolar collapse and increased normal aerated tissue independent of the degree of volemia. Along this line, experimental and clinical studies have shown that improvement in lung aeration is associated with better lung mechanics [49-51]. RMs improved oxygenation during hypervolemia, probably because of the higher amount of collapsed lung tissue, which may increase the effectiveness of RMs reversing atelectasis and decreasing intrapulmonary shunt. Gattinoni and colleagues [51] have shown that the beneficial effects of RMs are more pronounced in patients with higher lung weight and atelectasis. The lack of correlation between reduction in atelectasis and oxygenation after RMs in the HYPO and NORMO groups could also be explained by the redistribution of perfusion [52,53]. After RM, Est,L was reduced in HYPO but not in NORMO or HYPER groups. The improvement in Est,L in HYPO group could be explained by alveolar recruitment, whereas the lack of improvement in the other groups may be related to the combination of alveolar recruitment and the increase in interstitial and/or alveolar edema, with consequent increase in specific Est,L.

RMs increase alveolar fluid clearance [8] and aerated tissue, which may lead to reduced lung stretch and inflammatory mediator release [54]. Our data suggest that RMs in the HYPO and NORMO groups did not result in further damage of epithelial and endothelial cells or increased expression of inflammatory and fibrogenic mediators. In addition, RMs induced higher mRNA expression of VCAM-1 in NORMO and HYPER groups, but not of ICAM-1, which was presented higher in HYPER group regardless of RM. Conversely, in HYPO 

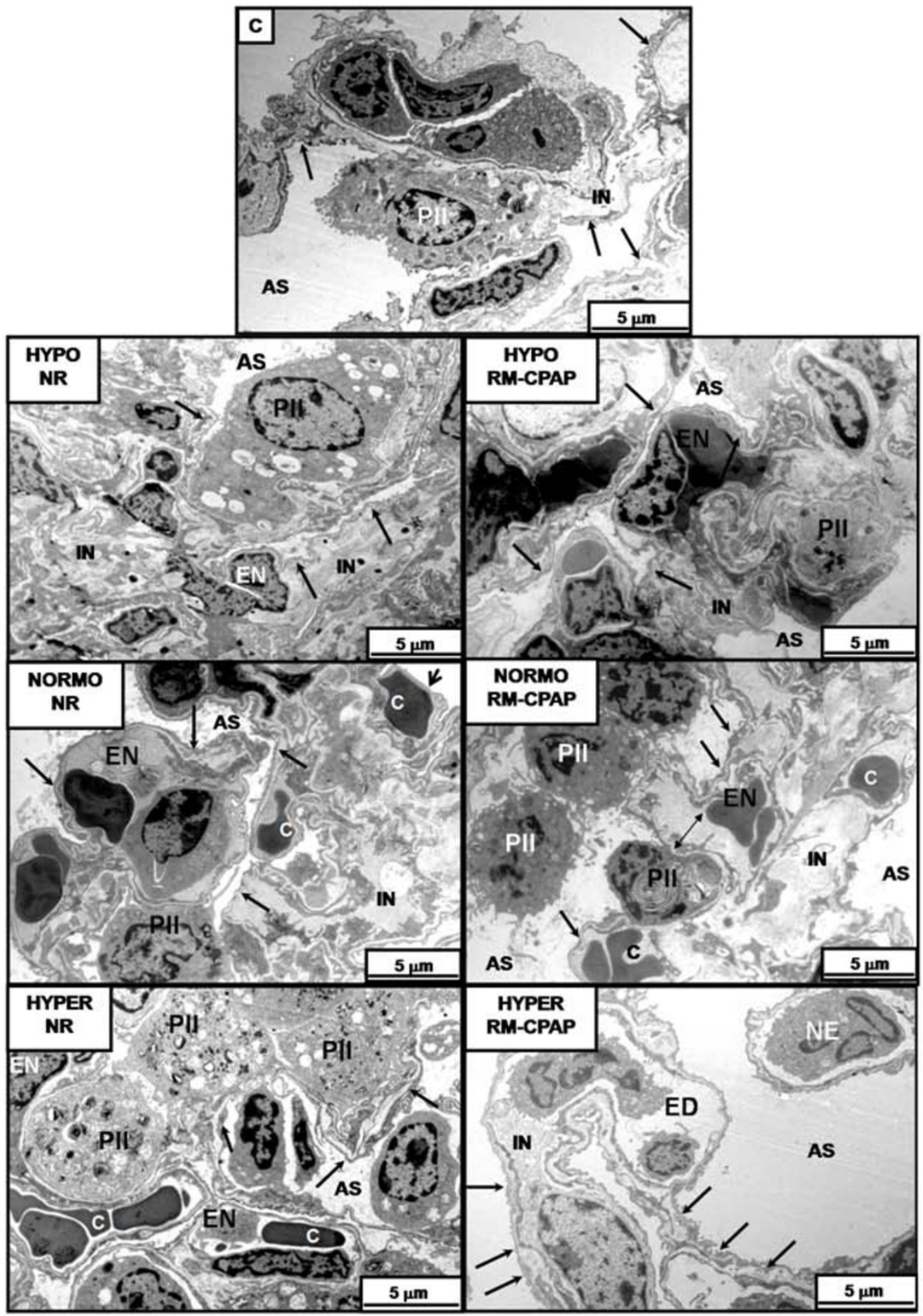

Figure 4 Electron microscopy of lung parenchyma. Animals were randomly assigned to hypovolemia (HYPO), normovolemia (NORMO) or hypervolemia (HYPER) with recruitment maneuver (RM-CPAP) or not (NR). Type II pneumocyte (PII) as well as alveolar capillary membrane were damaged in all acute lung injury groups. Note that the alveolar-capillary membrane is less damaged in the HYPO-RM-CPAP group (ellipse) compared with the other groups. In NORMO-RM-CPAP, there was a detachment of alveolar capillary membrane (arrow). In HYPER-RM-CPAP, note that alveolar compartmentalization is lost with disorganization of the alveolar cellular components. Photomicrographs are representative of data obtained from lung sections derived from six animals. EN, endothelial cell. 


\begin{tabular}{|c|c|c|c|c|c|c|}
\hline & \multicolumn{2}{|c|}{ HYPO } & \multicolumn{2}{|c|}{ NORMO } & \multicolumn{2}{|c|}{ HYPER } \\
\hline & NR & RM-CPAP & NR & RM-CPAP & NR & RM-CPAP \\
\hline Lung & $\begin{array}{c}2 \\
(2-3)\end{array}$ & $\begin{array}{c}2 \\
(2-2.25)\end{array}$ & $\begin{array}{c}2 \\
(1.75-3)\end{array}$ & $\begin{array}{c}2 \\
(2-3)\end{array}$ & $\begin{array}{c}3 \\
(2-3.25)\end{array}$ & $\begin{array}{l}4 \neq \S \\
(3-4)\end{array}$ \\
\hline Kidney & $\begin{array}{c}2 \\
(2-3)\end{array}$ & $\begin{array}{c}3 \\
(2-3.25)\end{array}$ & $\begin{array}{c}3 \\
(1.75-3)\end{array}$ & $\begin{array}{c}3 \\
(2-3)\end{array}$ & $\begin{array}{c}3 \\
(2.75-3.25)\end{array}$ & $\begin{array}{c}4 \\
(3-4)\end{array}$ \\
\hline Liver & $\begin{array}{c}2 \\
(2-2.25)\end{array}$ & $\begin{array}{c}2 \\
(2-3)\end{array}$ & $\begin{array}{c}2 \\
(2-3)\end{array}$ & $\begin{array}{c}2 \\
(2-3)\end{array}$ & $\begin{array}{c}2 \\
(2-3)\end{array}$ & $\begin{array}{c}3 \\
(2.75-3.25)\end{array}$ \\
\hline Villi & $\begin{array}{c}3 \\
(2-3)\end{array}$ & $\begin{array}{c}3 \\
(2.75-3.25)\end{array}$ & $\begin{array}{c}3 \\
(2-3)\end{array}$ & $\begin{array}{c}3 \\
(2.75-3)\end{array}$ & $\begin{array}{c}3 \\
(3-4)\end{array}$ & $\begin{array}{c}4 \\
(2.75-4)\end{array}$ \\
\hline
\end{tabular}

Semi-quantitative analysis of apoptotic cells in lung, kidney, liver, and small intestine villi. The apoptotic findings were graded as negative $=$ 0 , slight $=1$, moderate $=2$, high $=3$ and severe $=4$ in 10 non-coincident microscopic fields ( $\times 400$ magnification). A mean score was then calculated ( $0=$ normal lung parenchyma; $1=1-25 \% ; 2=26$ to $50 \% ; 3=51$ to $75 \% ; 4=76$ to $100 \%$ of structures altered). Animals were randomly assigned to hypovolemia (HYPO), normovolemia (NORMO) or hypervolemia (HYPER) with recruitment maneuver (RM-CPAP) or not $(N R)$. Values are the median ( $25^{\text {th }}$ percentile to $75^{\text {th }}$ percentile) of five animals per group. $¥$ Significantly different from HYPO-RM-CPAP $(P<$ 0.05). §Significantly different from NORMO-RM-CPAP $(P<0.05)$.

group after RM, the mRNA expression of VCAM-1 and ICAM-1 decreased, probably reflecting reduced shear stress.

RMs transiently increase lung stress [50], probably damaging the alveolar capillary membrane triggering inflammatory and fibrogenic responses $[9,12]$ and impairing net alveolar fluid clearance [8]. However, the potential of RMs to damage the lung is still a matter of debate [11]. In hypervolemia, our results suggest that despite an improvement in functional parameters, RMs are associated with increased detachment of the alveolar capillary membrane, injury of epithelial type II and endothelial cells, as well as an activation of inflammatory and fibrogenetic response. As previously discussed, hypervolemia per se may worsen lung injury, especially at the level of the alveolar capillary membrane. Our results suggest that the negative effects of hypervolemia on lung damage are potentiated by increased stress/strain induced by RMs.

The increase in different inflammatory mediators after RMs in hypervolemia cannot be explained by increased atelectasis and/or cyclic opening and closing of collapsed units. In fact, atelectasis was reduced after RMs in hypervolemia. Thus, the increase in gene expression of inflammatory mediators in the lung may have resulted from a single sustained inflation RM.

There are conflicting data on the potential of RMs to decompartmentalize lung inflammation [55,56]. Our results suggest that the combination of RMs with hypervolemia does not result in distal organ injury. Neverthe- less, we cannot extrapolate these results to longer periods of ventilation and/or the application of other strategies to recruit the lungs. Theoretically, the inflammatory process could spread to distal organs in the long term. On the other hand, more frequent RMs could accelerate and exacerbate our findings. Also, RMs with pressure profiles different from the sustained inflation, for example gradual increase of airway pressure, could lead to reduced stress and reduce the biological impact of the maneuver. Certainly, this issue deserves further investigation.

We observed greater injury of type II epithelial cells and gene expression of PCIII when lungs were recruited in hypervolemia. Not only are type II cells involved in surfactant production, they are also associated with repairing mechanisms of injured lungs [57]. Re-expansion of collapsed lung units may expose the alveoli to tensile and shear stresses stimulating fibroblasts and macrophages to synthesize collagen fibers [58]. Our results are in accordance with previous reports demonstrating increased procollagen mRNA expression in lungs submitted to high airway pressures [37].

\section{Limitations}

This study has several limitations. Firstly, we used a CLP model of sepsis. Thus, our results cannot be extended to other experimental models of sepsis or directly extrapolated to the clinical scenario. Secondly, the mortality of our sepsis model was relatively high (40\%). Thus, we cannot completely exclude that there was a kind of natural bias and a 'sepsis-tolerating' population has been unin- 


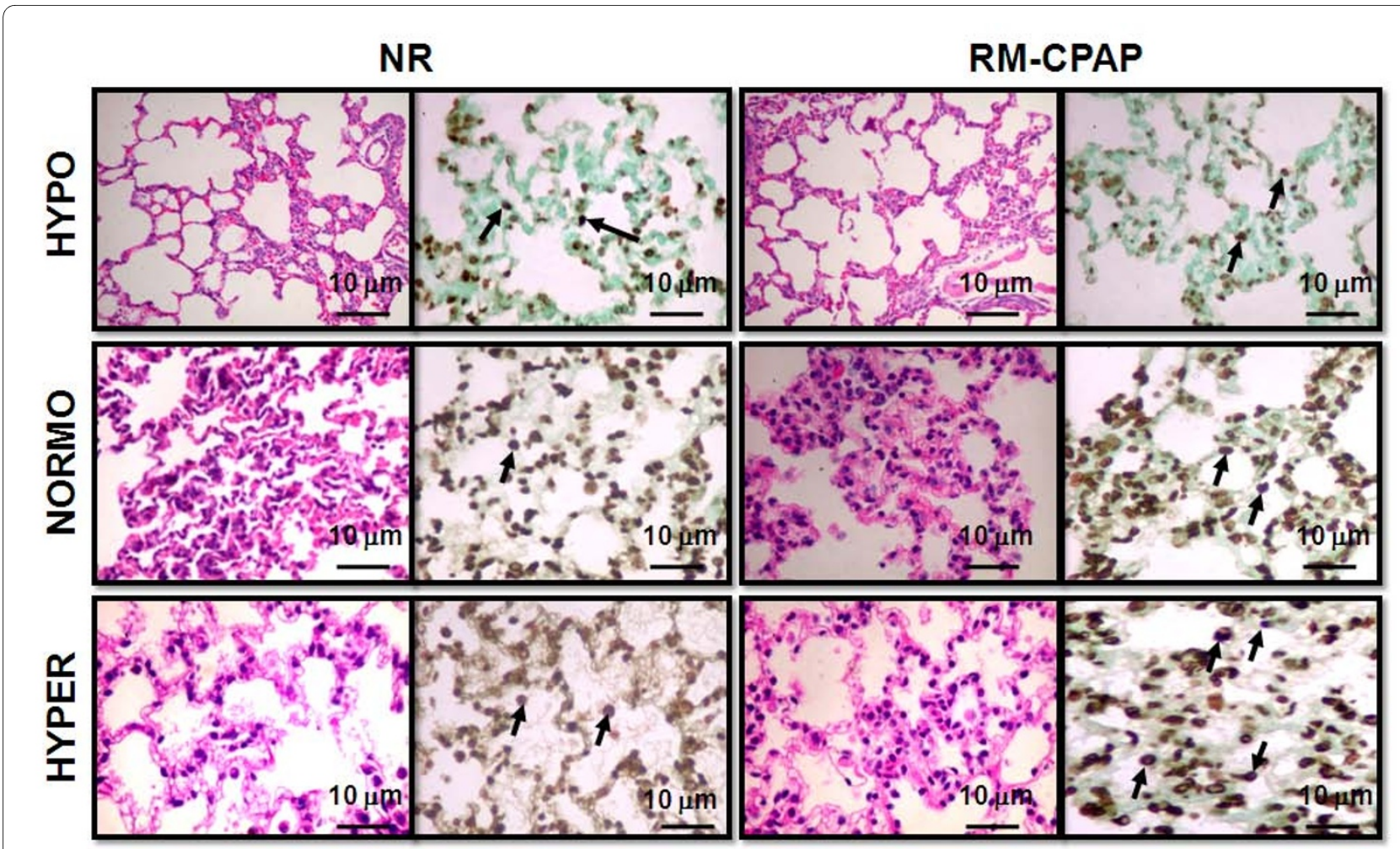

Figure 5 Representative photomicrographs of lung stained with H\&E (left panels) and TUNEL (right panels). Animals were randomly assigned to hypovolemia (HYPO), normovolemia (NORMO) or hypervolemia (HYPER) with recruitment maneuver (RM-CPAP) or not (NR). Note that in the HYPER group, the number of apoptotic lung epithelial cells was higher than in NORMO and HYPO (arrows). Photographs were taken at an original magnification of $\times 200$.

tentionally selected. However, if hypervolemia was able to produce and potentiate lung damage after RMs in this subgroup, effects would have been even more pronounced in a less 'sepsis-tolerating' population. Thirdly, the observation time was relatively short (one hour), precluding extrapolation of our findings to longer periods of ventilation. The one-hour period was chosen based on our experience with this model and taking the time needed to detect alterations in the proinflammatory and fibrogenetic response of the lungs due to mechanical ventilation in rats $[21,59]$. As we identified that the proinflammatory response was activated and the alveolocapillary membrane was damaged in the short period, we speculate that the protein levels of the inflammatory cytokines would be higher in the lungs with hypervolemia (specially after RMs) and achieve distal organs due to decompartmentalization if the observation period would have been extended. Fourthly, hypervolemia was achieved by infusion of gelatin. Different results may be observed with other types of colloids or even crystalloids. Finally, the RM was performed as sustained inflation. Recent studies have reported reduced lung injury and fewer adverse hemodynamic effects with other types of RM [12]. However, sustained inflation is the most commonly used RM in clinical practice [11].

\section{Conclusions}

In the present model of sepsis-induced ALI, the use of RMs during hypervolemia reduced alveolar collapse and improved oxygenation and lung mechanics at the expense of alveolar capillary membrane damage, increased edema, and higher gene expression of inflammatory and fibrogenic mediators. Our data suggest that hypervolemia, but not normo- or hypovolemia, may induce and also potentiate lung damage after RMs while not affecting distal organs. Therefore, volemic status should be controlled during RMs, but this hypothesis must be tested in further clinical studies.

\section{Key messages}

- Hypervolemia increased lung W/D ratio and alveolar collapse leading to impairment in oxygenation and Est,L. Furthermore, hypervolemia was associated with alveolar and endothelium damage as well as increased mRNA expression of IL-6, VCAM-1 and ICAM-1 in lung tissue.

- RMs reduced alveolar collapse regardless of volemic status. 

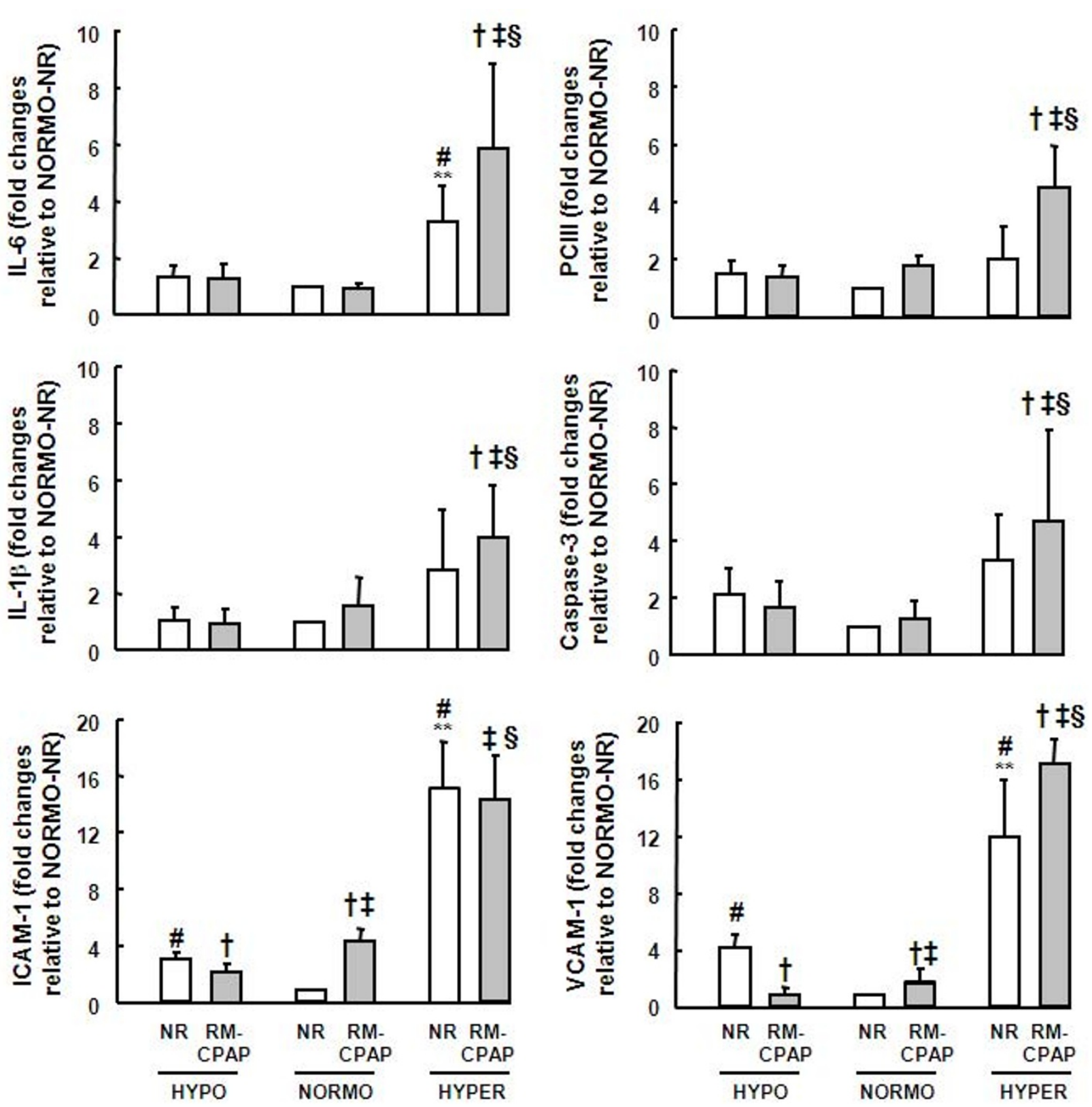

Figure 6 RT-PCR analysis of caspase-3, IL-6, IL1- $\beta$, type III procollagen (PCIII), intercellular adhesion molecule 1 (ICAM-1), and vascular cell adhesion molecule 1 (VCAM-1) mRNA expressions in lung tissue. Animals were randomly assigned to hypovolemia (HYPO), normovolemia (NOR$\mathrm{MO}$ ) or hypervolemia (HYPER) with recruitment maneuver (RM-CPAP) or not (NR). The y axis represents fold increase compared with NORMO-NR. Values are mean \pm standard error of the mean of five animals in each group. †Significantly different from $N R(P<0.05)$. ** Significantly different from $\mathrm{HYPO}$ NR $(P<0.05)$. $¥$ Significantly different from HYPO-RM-CPAP $(P<0.05)$. \#Significantly different from NORMO-NR $(P<0.05)$. §Significantly different from NORMO-RM-CPAP $(P<0.05)$.

- During hypervolemia, RMs improved oxygenation and lung mechanics at the expense of alveolar capillary membrane damage, increased edema, and higher gene expression of inflammatory and fibrogenic mediators. Therefore, hypervolemia, but not normo or hypovolemia, may potentiate lung damage after RMs.
- Volemic status should be controlled and hypervolemia avoided during RMs, but this hypothesis must be tested in further clinical studies.

\section{Abbreviations}

ALI: acute lung injury; ANOVA: analysis of variance; ARDS: acute respiratory distress syndrome; CLP: cecal ligation and puncture; Est,L: static lung elastance; $\mathrm{FiO}_{2}$ : fraction of inspired oxygen; GAPDH: glyceraldehyde-3-phosphate dehydrogenase; H\&E: hematoxylin and eosin; HYPER: hypervolemia; HYPO: hypov- 
olemia; ICAM: intercellular adhesion molecule; IL: interleukin; IVC: inferior vena cava; MAP: mean arterial pressure; NORMO: normovolemia; PII: type II pneumocytes; $\mathrm{PaCO}_{2}$ : arterial carbon dioxide partial pressure; $\mathrm{PaO}_{2}$ : arterial oxygen partial pressure; PCIII: type III procollagen; PEEP: positive-end expiratory pressure; pHa: arterial pH; RA: right atrium; RMs: recruitment maneuvers; RR: respiratory rate; RT-PCR: reverse transcription polymerase chain reaction; TUNEL: Terminal deoxynucleotidyl Transferase Biotin-dUTP Nick End Labeling; VCAM: vascular cell adhesion molecule; VILI: ventilator-induced lung injury; $\mathrm{V}_{\mathrm{T}}$ : tidal volume; $\mathrm{W} /$ D: wet-to-dry; ZEEP: zero end-expiratory pressure.

\section{Competing interests}

The authors declare that they have no competing interests.

\section{Authors' contributions}

PLS contributed to animal preparation, performance of experimental work, analysis of mechanical and histological data, statistical analysis, and writing of the manuscript. FFC contributed to animal preparation, performance of experimental work, preliminary data analysis, and drafting of the manuscript. LCF contributed to animal preparation, performance of experimental work, analysis of mechanical data, and drafting of the manuscript. GPO contributed to animal preparation, performance of experimental work, and analysis of mechanical and morphometrical data. CSS contributed to animal preparation, performance of experimental work, analysis of mechanical and morphometrical data, and drafting of the manuscript. DSO contributed to analysis of molecular biology data, and drafting of the manuscript. TMG contributed to analysis of molecular biology data, and drafting of the manuscript. NNR contributed to analysis of echocardiography, and drafting of the manuscript. RCG contributed to analysis of echocardiography, and drafting of the manuscript. CSNBG contributed to analysis of histological data, and drafting of the manuscript. MMM contributed to analysis of molecular biology data, and drafting of the manuscript. VLC contributed to analysis of histological data, and drafting of the manuscript. MGA contributed to experimental design, writing of the manuscript, and supervision and overview of entire project. PP contributed to experimental design, writing of the manuscript, and supervision and overview of entire project. PRMR contributed to experimental design, supervision of experimental work, statistical analysis, writing of the manuscript, and supervision and overview of entire project. All authors revised the manuscript and approved its final version

\section{Acknowledgements}

This work was supported by the Centres of Excellence Program (PRONEXFAPERJ), Brazilian Council for Scientific and Technological Development (CNPq), Carlos Chagas Filho, Rio de Janeiro State Research Supporting Foundation (FAPERJ), Coordination for the Improvement of Higher Education Personnel (CAPES), São Paulo State Research Supporting Foundation (FAPESP). The authors would like to express their gratitude to Mr. Andre Benedito da Silva for animal care, Mrs. Jaqueline Lima do Nascimento, Mariana B G Oliveira, Felipe Ornellas, and Humberto Carreira Junior for their skilful technical assistance during the experiments, Mrs. Ana Lucia Neves da Silva for her help with microscopy, Prof. Carmen Valente Barbas for her suggestions during the experiments, and Mrs. Moira Elizabeth Schöttler and Claudia Buchweitz for assistance in editing the manuscript.

\section{Author Details}

'Laboratory of Pulmonary Investigation, Carlos Chagas Filho Institute of Biophysics, Federal University of Rio de Janeiro, Av. Carlos Chagas Filho, s/n, Rio de Janeiro, 21949-902, Brazil, 2Laboratory of Cellular and Molecular Physiology, Carlos Chagas Filho Institute of Biophysics, Federal University of Rio de Janeiro, Av. Carlos Chagas Filho, s/n, Rio de Janeiro, 21949-902, Brazil, 3Laboratory of Cell and Molecular Cardiology, Carlos Chagas Filho Institute of Biophysics, Federal University of Rio de Janeiro, Av. Carlos Chagas Filho, s/n, Rio de Janeiro, 21949-902, Brazil, 4Department of Physiology and Pharmacology, Fluminense Federal University, Rua Professor Hernani Pires de Melo 101, Niterói, Rio de Janeiro, 24210-130, Brazil, ${ }^{5}$ Department of Pathology, Faculty of Medicine, University of São Paulo, Dr. Arnaldo Street, 455, Sao Paulo, 01246-903, Brazil, 6Pulmonary Engineering Group, Department of Anaesthesiology and Intensive Care Therapy, University Hospital Carl Gustav Carus, Technical University of Dresden, Fetscherstr. 74, 01307 Dresden, Germany and 7Department of Ambient, Health and Safety, University of Insubria, Servizio di Anestesia B, Ospedale di Circolo e Fondazione Macchi viale Borri 57, 21100 Varese, Italy
Received: 6 February 2010 Revised: 21 April 2010 Accepted: 14 June 2010 Published: 14 June 2010

\section{References}

1. Putensen C, Theuerkauf N, Zinserling J, Wrigge H, Pelosi P: Meta-analysis: ventilation strategies and outcomes of the acute respiratory distress syndrome and acute lung injury. Ann Intern Med 2009, 151:566-576.

2. Mercat A, Richard JC, Vielle B, Jaber S, Osman D, Diehl JL, Lefrant JY, Prat G, Richecoeur J, Nieszkowska A, Gervais C, Baudot J, Bouadma L, Brochard L: Positive end-expiratory pressure setting in adults with acute lung injury and acute respiratory distress syndrome: a randomized controlled trial. JAMA 2008, 299:646-655.

3. Meade MO, Cook DJ, Guyatt GH, Slutsky AS, Arabi YM, Cooper DJ, Davies AR, Hand LE, Zhou Q, Thabane L, Austin P, Lapinsky S, Baxter A, Russell J, Skrobik Y, Ronco JJ, Stewart TE: Ventilation strategy using low tidal volumes, recruitment maneuvers, and high positive end-expiratory pressure for acute lung injury and acute respiratory distress syndrome: a randomized controlled trial. JAMA 2008, 299:637-645.

4. Hodgson C, Keating JL, Holland AE, Davies AR, Smirneos L, Bradley SJ, Tuxen D: Recruitment manoeuvres for adults with acute lung injury receiving mechanical ventilation. Cochrane Database Syst Rev 2009:CD006667.

5. Vlahakis NE, Hubmayr RD: Cellular stress failure in ventilator-injured lungs. Am J Respir Crit Care Med 2005, 171:1328-1342.

6. Frank JA, MCAuley DF, Gutierrez JA, Daniel BM, Dobbs L, Matthay MA: Differential effects of sustained inflation recruitment maneuvers on alveolar epithelial and lung endothelial injury. Crit Care Med 2005, 33:181-188. discussion 254-185

7. de Prost N, Dreyfuss D, Saumon G: Evaluation of two-way protein fluxes across the alveolo-capillary membrane by scintigraphy in rats: effect of lung inflation. J Appl Physiol 2007, 102:794-802.

8. Constantin JM, Cayot-Constantin S, Roszyk L, Futier E, Sapin V, Dastugue B, Bazin JE, Rouby JJ: Response to recruitment maneuver influences net alveolar fluid clearance in acute respiratory distress syndrome. Anesthesiology 2007, 106:944-951.

9. Riva DR, Oliveira MB, Rzezinski AF, Rangel G, Capelozzi VL, Zin WA, Morales MM, Pelosi P, Rocco PR: Recruitment maneuver in pulmonary and extrapulmonary experimental acute lung injury. Crit Care Med 2008, 36:1900-1908

10. Fu Z, Costello ML, Tsukimoto K, Prediletto R, Elliott AR, Mathieu-Costello O, West JB: High lung volume increases stress failure in pulmonary capillaries. J Appl Physiol 1992, 73:123-133.

11. Fan E, Wilcox ME, Brower RG, Stewart TE, Mehta S, Lapinsky SE, Meade MO, Ferguson ND: Recruitment maneuvers for acute lung injury: a systematic review. Am J Respir Crit Care Med 2008, 178:1156-1163.

12. Steimback PW, Oliveira GP, Rzezinski AF, Silva PL, Garcia CS, Rangel G, Morales MM, Lapa ESJR, Capelozzi VL, Pelosi P, Rocco PR: Effects of frequency and inspiratory plateau pressure during recruitment manoeuvres on lung and distal organs in acute lung injury. Intensive Care Med 2009, 35:1120-1128.

13. Borges JB, Okamoto VN, Matos GF, Caramez MP, Arantes PR, Barros F, Souza CE, Victorino JA, Kacmarek RM, Barbas CS, Carvalho CR, Amato MB: Reversibility of lung collapse and hypoxemia in early acute respiratory distress syndrome. Am J Respir Crit Care Med 2006, 174:268-278.

14. Rivers EP: Fluid-management strategies in acute lung injury--liberal, conservative, or both? N Engl J Med 2006, 354:2598-2600.

15. Schuster DP: Fluid management in ARDS: "keep them dry" or does it matter? Intensive Care Med 1995, 21:101-103.

16. Jia X, Malhotra A, Saeed M, Mark RG, Talmor D: Risk factors for ARDS in patients receiving mechanical ventilation for $>48 \mathrm{~h}$. Chest 2008, 133:853-861.

17. Rosenberg AL, Dechert RE, Park PK, Bartlett RH: Review of a large clinical series: association of cumulative fluid balance on outcome in acute lung injury: a retrospective review of the ARDSnet tidal volume study cohort. J Intensive Care Med 2009, 24:35-46.

18. Rocco PR, Pelosi P: Pulmonary and extrapulmonary acute respiratory distress syndrome: myth or reality? Curr Opin Crit Care 2008, 14:50-55.

19. Hubbard WJ, Choudhry M, Schwacha MG, Kerby JD, Rue LW, Bland KI, Chaudry IH: Cecal ligation and puncture. Shock 2005, 24(Suppl 1):52-57.

20. Oliveira GP, Oliveira MB, Santos RS, Lima LD, Dias CM, Ab' Saber AM, Teodoro WR, Capelozzi VL, Gomes RN, Bozza PT, Pelosi P, Rocco PR: 
Intravenous glutamine decreases lung and distal organ injury in an experimental model of abdominal sepsis. Crit Care 2009, 13:R74.

21. Passaro CP, Silva PL, Rzezinski AF, Abrantes S, Santiago VR, Nardelli L, Santos RS, Barbosa CM, Morales MM, Zin WA, Amato MB, Capelozzi VL, Pelosi P, Rocco PR: Pulmonary lesion induced by low and high positive end-expiratory pressure levels during protective ventilation in experimental acute lung injury. Crit Care Med 2009, 37:1011-1017.

22. Baydur A, Behrakis PK, Zin WA, Jaeger M, Milic-Emili J: A simple method for assessing the validity of the esophageal balloon technique. Am Rev Respir Dis 1982, 126:788-791.

23. Baydur A, Sassoon CS, Stiles CM: Partitioning of respiratory mechanics in young adults. Effects of duration of anesthesia. Am Rev Respir Dis 1987, 135:165-172.

24. Cheitlin MD, Armstrong WF, Aurigemma GP, Beller GA, Bierman FZ, Davis $J$, Douglas PS, Faxon DP, Gillam LD, Kimball TR, Kussmaul WG, Pearlman AS, Philbrick JT, Rakowski H, Thys DM, Antman EM, Smith SC Jr, Alpert JS, Gregoratos G, Anderson JL, Hiratzka LF, Faxon DP, Hunt SA, Fuster V, Jacobs AK, Gibbons RJ, Russell RO, ACC, AHA, ASE: ACC/AHA/ASE 2003 Guideline Update for the Clinical Application of Echocardiography: summary article. A report of the American College of Cardiology/ American Heart Association Task Force on Practice Guidelines (ACC) AHA/ASE Committee to Update the 1997 Guidelines for the Clinical Application of Echocardiography). J Am Soc Echocardiogr 2003, 16:1091-1110.

25. Weibel ER: Morphometry: stereological theory and practical methods. Models of Lung Disease-Microscopy and Structural Methods 1990:199-247.

26. Leite-Junior JH, Garcia CS, Souza-Fernandes AB, Silva PL, Ornellas DS, Larangeira AP, Castro-Faria-Neto HC, Morales MM, Negri EM, Capelozzi VL, Zin WA, Pelosi P, Bozza PT, Rocco PR: Methylprednisolone improves lung mechanics and reduces the inflammatory response in pulmonary but not in extrapulmonary mild acute lung injury in mice. Crit Care Med 2008, 36:2621-2628

27. Peterson BT, Brooks JA, Zack AG: Use of microwave oven for determination of postmortem water volume of lungs. J Appl Physiol 1982, 52:1661-1663.

28. Remick DG, Newcomb DE, Bolgos GL, Call DR: Comparison of the mortality and inflammatory response of two models of sepsis: lipopolysaccharide vs. cecal ligation and puncture. Shock 2000, 13:110-116

29. Rittirsch D, Huber-Lang MS, Flierl MA, Ward PA: Immunodesign of experimental sepsis by cecal ligation and puncture. Nat Protoc 2009, 4:31-36.

30. Youn HJ, Rokosh G, Lester SJ, Simpson P, Schiller NB, Foster E: Twodimensional echocardiography with a $15-\mathrm{MHz}$ transducer is a promising alternative for in vivo measurement of left ventricular mass in mice. J Am Soc Echocardiogr 1999, 12:70-75

31. Mitaka C, Nagura T, Sakanishi N, Tsunoda Y, Amaha K: Two-dimensional echocardiographic evaluation of inferior vena cava, right ventricle, and left ventricle during positive-pressure ventilation with varying levels of positive end-expiratory pressure. Crit Care Med 1989, 17:205-210.

32. dos Santos CC, Slutsky AS: The contribution of biophysical lung injury to the development of biotrauma. Annu Rev Physiol 2006, 68:585-618.

33. Kulkarni AC, Kuppusamy P, Parinandi N: Oxygen, the lead actor in the pathophysiologic drama: enactment of the trinity of normoxia, hypoxia, and hyperoxia in disease and therapy. Antioxid Redox Signal 2007 9:1717-1730.

34. Fanelli V, Mascia L, Puntorieri V, Assenzio B, Elia V, Fornaro G, Martin EL, Bosco M, Delsedime L, Fiore T, Grasso S, Ranieri VM: Pulmonary atelectasis during low stretch ventilation: "open lung" versus "lung rest" strategy. Crit Care Med 2009, 37:1046-1053.

35. Panacek EA, Marshall JC, Albertson TE, Johnson DH, Johnson S, MacArthur RD, Miller M, Barchuk WT, Fischkoff S, Kaul M, Teoh L, Van Meter L, Daum L, Lemeshow S, Hicklin G, Doig C: Efficacy and safety of the monoclonal anti-tumor necrosis factor antibody $F\left(a b^{\prime}\right) 2$ fragment afelimomab in patients with severe sepsis and elevated interleukin- 6 levels. Crit Care Med 2004, 32:2173-2182.

36. Rocco PR, Negri EM, Kurtz PM, Vasconcellos FP, Silva GH, Capelozzi VL, Romero PV, Zin WA: Lung tissue mechanics and extracellular matrix remodeling in acute lung injury. Am J Respir Crit Care Med 2001, 164:1067-1071.
37. de Carvalho ME, Dolhnikoff M, Meireles SI, Reis LF, Martins MA Deheinzelin D: Effects of overinflation on procollagen type III expression in experimental acute lung injury. Crit Care 2007, 11:R23.

38. Slee EA, Harte MT, Kluck RM, Wolf BB, Casiano CA, Newmeyer DD, Wang HG, Reed JC, Nicholson DW, Alnemri ES, Green DR, Martin SJ: Ordering the cytochrome $c$-initiated caspase cascade: hierarchical activation of caspases-2, $-3,-6,-7,-8$, and -10 in a caspase-9-dependent manner. $J$ Cell Biol 1999, 144:281-292.

39. Miyao N, Suzuki Y, Takeshita K, Kudo H, Ishii M, Hiraoka R, Nishio K, Tamatani T, Sakamoto S, Suematsu M, Tsumura H, Ishizaka A, Yamaguchi K: Various adhesion molecules impair microvascular leukocyte kinetics in ventilator-induced lung injury. Am J Physiol Lung Cell Mol Physiol 2006, 290:L1059-1068.

40. Dellinger RP, Levy MM, Carlet JM, Bion J, Parker MM, Jaeschke R, Reinhart K, Angus DC, Brun-Buisson C, Beale R, Calandra T, Dhainaut JF, Gerlach H, Harvey M, Marini JJ, Marshall J, Ranieri M, Ramsay G, Sevransky J, Thompson BT, Townsend S, Vender JS, Zimmerman JL, Vincent JL: Surviving Sepsis Campaign: international guidelines for management of severe sepsis and septic shock: 2008. Intensive Care Med 2008, 34:17-60.

41. van der Heijden M, Verheij J, van Nieuw Amerongen GP, Groeneveld AB: Crystalloid or colloid fluid loading and pulmonary permeability, edema, and injury in septic and nonseptic critically ill patients with hypovolemia. Crit Care Med 2009, 37:1275-1281.

42. Gattinoni L, Pesenti A: The concept of "baby lung". Intensive Care Med 2005, 31:776-784

43. Dos Santos CC, Slutsky AS: Invited review: mechanisms of ventilatorinduced lung injury: a perspective. J App/ Physio/ 2000, 89:1645-1655

44. Lopez-Aguilar J, Piacentini E, Villagra A, Murias G, Pascotto S, SaenzValiente A, Fernandez-Segoviano P, Hotchkiss JR, Blanch L: Contributions of vascular flow and pulmonary capillary pressure to ventilatorinduced lung injury. Crit Care Med 2006, 34:1106-1112.

45. Negrini $\mathrm{D}$, Tenstad $\mathrm{O}$, Wiig $\mathrm{H}$ : Interstitial exclusion of albumin in rabbit lung during development of pulmonary oedema. J Physiol 2003, 548:907-917.

46. Plotz FB, Slutsky AS, van Vught AJ, Heijnen CJ: Ventilator-induced lung injury and multiple system organ failure: a critical review of facts and hypotheses. Intensive Care Med 2004, 30:1865-1872.

47. Barbas CS, de Matos GF, Pincelli MP, da Rosa Borges E, Antunes T, de Barros JM, Okamoto V, Borges JB, Amato MB, de Carvalho CR: Mechanical ventilation in acute respiratory failure: recruitment and high positive end-expiratory pressure are necessary. Curr Opin Crit Care 2005, 11:18-28.

48. Oczenski W, Hormann C, Keller C, Lorenzl N, Kepka A, Schwarz S, Fitzgerald $\mathrm{RD}$ : Recruitment maneuvers during prone positioning in patients with acute respiratory distress syndrome. Crit Care Med 2005, 33:54-61. quiz 62

49. Carvalho AR, Spieth PM, Pelosi P, Vidal Melo MF, Koch T, Jandre FC, Giannella-Neto A, de Abreu MG: Ability of dynamic airway pressure curve profile and elastance for positive end-expiratory pressure titration. Intensive Care Med 2008, 34:2291-2299.

50. Henzler D, Pelosi P, Bensberg R, Dembinski R, Quintel M, Pielen V, Rossaint $R$, Kuhlen R: Effects of partial ventilatory support modalities on respiratory function in severe hypoxemic lung injury. Crit Care Med 2006, 34:1738-1745

51. Gattinoni L, Caironi P, Cressoni M, Chiumello D, Ranieri VM, Quintel M, Russo S, Patroniti N, Cornejo R, Bugedo G: Lung recruitment in patients with the acute respiratory distress syndrome. N Engl J Med 2006, 354:1775-1786.

52. Cressoni M, Caironi P, Polli F, Carlesso E, Chiumello D, Cadringher P, Quintel M, Ranieri VM, Bugedo G, Gattinoni L: Anatomical and functional intrapulmonary shunt in acute respiratory distress syndrome. Crit Care Med 2008, 36:669-675.

53. Carvalho AR, Spieth PM, Pelosi P, Beda A, Lopes AJ, Neykova B, Heller AR, Koch T, Gama de Abreu M: Pressure support ventilation and biphasic positive airway pressure improve oxygenation by redistribution of pulmonary blood flow. Anesth Analg 2009, 109:856-865.

54. Koh WJ, Suh GY, Han J, Lee SH, Kang EH, Chung MP, Kim H, Kwon OJ: Recruitment maneuvers attenuate repeated derecruitment-associated lung injury. Crit Care Med 2005, 33:1070-1076. 
55. Talmor D, Sarge T, Legedza A, O'Donnell CR, Ritz R, Loring SH, Malhotra A: Cytokine release following recruitment maneuvers. Chest 2007, 132:1434-1439.

56. Halbertsma FJ, Vaneker M, Pickkers P, Neeleman C, Scheffer GJ, Hoeven van der JG: A single recruitment maneuver in ventilated critically ill children can translocate pulmonary cytokines into the circulation. J Crit Care 2010, 25:10-15.

57. Matthay MA, Robriquet $L$, Fang $X$ : Alveolar epithelium: role in lung fluid balance and acute lung injury. Proc Am Thorac Soc 2005, 2:206-213.

58. Garcia CS, Rocco PR, Facchinetti LD, Lassance RM, Caruso P, Deheinzelin D, Morales MM, Romero PV, Faffe DS, Zin WA: What increases type III procollagen mRNA levels in lung tissue: stress induced by changes in force or amplitude? Respir Physiol Neurobiol 2004, 144:59-70.

59. Saddy F, Oliveira GP, Garcia CS, Nardelli LM, Rzezinski AF, Ornellas DS, Morales MM, Capelozzi VL, Pelosi P, Rocco PR: Assisted ventilation modes reduce the expression of lung inflammatory and fibrogenic mediators in a model of mild acute lung injury. Intensive Care Med 2010.

doi: $10.1186 /$ cc9063

Cite this article as: Silva et al., Hypervolemia induces and potentiates lung damage after recruitment maneuver in a model of sepsis-induced acute lung injury Critical Care 2010, 14:R114

Submit your next manuscript to BioMed Central and take full advantage of:

- Convenient online submission

- Thorough peer review

- No space constraints or color figure charges

- Immediate publication on acceptance

- Inclusion in PubMed, CAS, Scopus and Google Scholar

- Research which is freely available for redistribution

Submit your manuscript at www.biomedcentral.com/submit
C) Biomed Central 